Review

\title{
Breast Cancer Heterogeneity
}

\author{
Caterina Fumagalli *(1) and Massimo Barberis $(\mathbb{C}$
}

Division of Pathology, IEO, European Institute of Oncology IRCCS, 20141 Milan, Italy; massimo.barberis@ieo.it

* Correspondence: caterina.fumagalli@ieo.it

\begin{abstract}
Breast tumor heterogeneity is a major challenge in the clinical management of breast cancer patients. Both inter-tumor and intra-tumor heterogeneity imply that each breast cancer (BC) could have different prognosis and would benefit from specific therapy. Breast cancer is a dynamic entity, changing during tumor progression and metastatization and this poses fundamental issues to the feasibility of a personalized medicine approach. The most effective therapeutic strategy for patients with recurrent disease should be assessed evaluating biopsies obtained from metastatic sites. Furthermore, the tumor progression and the treatment response should be strictly followed and radiogenomics and liquid biopsy might be valuable tools to assess BC heterogeneity in a non-invasive way.
\end{abstract}

Keywords: breast cancer; inter-tumor heterogeneity; intra-tumor heterogeneity

check for updates

Citation: Fumagalli, C.; Barberis, M. Breast Cancer Heterogeneity. Diagnostics 2021, 11, 1555. https: / /doi.org/10.3390/ diagnostics11091555

Academic Editor: Mauro Giuseppe Mastropasqua

Received: 20 July 2021

Accepted: 26 August 2021

Published: 27 August 2021

Publisher's Note: MDPI stays neutral with regard to jurisdictional claims in published maps and institutional affiliations.

Copyright: (C) 2021 by the authors. Licensee MDPI, Basel, Switzerland. This article is an open access article distributed under the terms and conditions of the Creative Commons Attribution (CC BY) license (https:// creativecommons.org/licenses/by/ $4.0 /)$.

\section{Introduction}

Breast cancer (BC) is the most common female malignancy [1] and, although great efforts have been made to develop effective treatment strategies, it still remains the leading cause of tumor-related mortality in women worldwide. Breast cancer is typically a highly heterogeneous disease. Breast tumor heterogeneity has been observed and described since the nineteenth century [2] and these differences have served as the basis for disease classification. Hawkins et al. in 1988 reported variations in estrogen receptor concentration due to variations in tissue cellularity [3]. Breast tumor heterogeneity was observed among different patients (inter-tumor heterogeneity) and even within each individual tumor (intra-tumor heterogeneity), occurring as spatial and temporal heterogeneity [4] (Figure 1). The spatial heterogeneity involves distinct areas within a tumor that have differences at the phenotypic, transcriptomic, epigenetic and genomic levels; the temporal heterogeneity refers to variations occurring over time during tumor progression between primary and metastasis or among different metastatic lesions (intra-metastatic heterogeneity) [5]. Indeed, the tumor evolution itself as well as the therapy-induced clonal selection could result in intra-tumor or intra-metastases heterogeneity. In this scenario, even the microenvironment, equally affected by spatial heterogeneity phenomena, could boost the tumor heterogeneity. Actually the interactions between BC and stromal cells, the presence of chronic inflammation, the levels of nitric oxide and reactive oxygen species secretion and the extracellular matrix, as scaffold for protein and cell-specific trafficking, are some of the factors that could influence tumor development and progression [6,7]. 

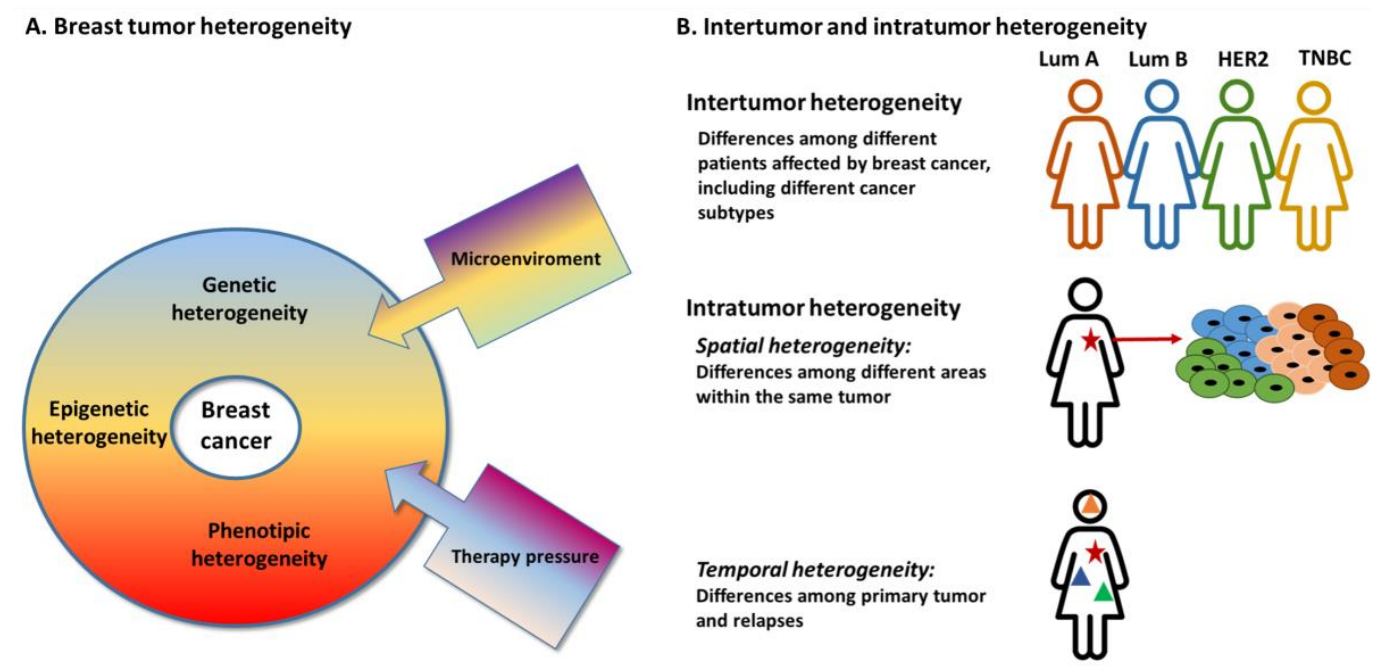

Figure 1. Breast tumor heterogeneity. (A) Factors that contribute to breast tumor heterogeneity; (B) Type of breast tumor heterogeneity: Inter-tumor and intra-tumor heterogeneity. Star: primary tumor, Triangles: relapses.

\section{Inter-Tumor Heterogeneity}

Inter-tumor heterogeneity reflects differences observed among different patients with BC. Traditionally, inter-tumor heterogeneity has been associated with different BC histological subtypes, treatment sensitivity response, and clinical outcomes. According to estrogen and progesterone receptors (ER and PR) status, Ki67 proliferation index and HER2 expressions, BC are grouped in Luminal-A (ER ${ }^{+}$and /or $\mathrm{PR}^{+}, \mathrm{Ki} 67<20$, HER2 ${ }^{-}$), Luminal B- $\left(\mathrm{ER}^{+}\right.$and /or PR $\left.{ }^{+}, \mathrm{Ki} 67 \geq 20, \mathrm{HER} 2^{-}\right)$, Luminal B ${ }^{+}\left(\mathrm{ER}^{+}\right.$and $/$or $\left.\mathrm{PR}^{+}, \mathrm{HER}^{+}\right)$, $\mathrm{HER}^{+}$non-Luminal $\left(\mathrm{ER}^{-}, \mathrm{PR}^{-}, \mathrm{HER} 2^{+}\right)$, and triple-negative $\left(\mathrm{ER}^{-}, \mathrm{PR}^{-}, \mathrm{HER}{ }^{-}\right)$. These $\mathrm{BC}$ subgroups have different prognosis and specific therapy response. In detail, luminal $A$ and luminal $B$ are the prevalent $B C$ subtypes and have been associated with a better outcome [8], whereas an aggressive course has been reported for triple negative tumors [9]. Moreover, the presence of ER or HER2 positivity leads to endocrine therapy benefit or target-therapy sensitivity, respectively $[10,11]$, while immunotherapy treatments have been proposed for triple negative tumors $[12,13]$. In this scenario, immunogenic biomarkers including tumor mutational burden (TMB), immune gene expression and mismatch repair deficiency (MMRd) are of paramount importance for selecting who could more likely benefit from immunotherapy regimens. The different $\mathrm{BC}$ subtypes show different biomarkers prevalence. In detail, hormone receptor (HR) negative breast cancers are characterized by a higher TMB, immune gene expression and MMRd frequency compared with HR positive tumors. Instead, HER2 negative BCs have a lower TMB and downregulation of immune gene expression compared to HER2 positive BCs. These results suggest that HR negative and HER2-positive tumors may be more likely to benefit from immunotherapies [14].

In addition, each $\mathrm{BC}$ subtype has distinctive molecular hallmarks [15]. Next-generation sequencing (NGS) analysis of primary breast tumors revealed that very few cancer-related genes are mutated at high frequency, altered in more than $10 \%$ of all $\mathrm{BC}$ subtypes, namely GATA3, TP53 and PIK3CA. However, a high inter-tumor heterogeneity has been observed. In detail, TP53 mutations were more common in triple negative tumors, whereas PIK3CA mutations were more frequent in Luminal/HER2 negative and HER2 positive tumors [16]. Besides, peculiar genetic aberrations are associated with specific $\mathrm{BC}$ subtypes, as $\mathrm{CDH1}$ mutations in Luminal A tumors, CCND1, FGF3, FGF19, and FGFR1 copy gains in estrogen receptor positive $B C$, whereas $M Y C$ amplification, NF1 mutations and BRCA1/2 pathogenic variants were recurrent in triple negative tumors [16-19].

Table 1 summarizes the main epidemiological, phenotypical and genetic characteristics of BC subtypes. 
Table 1. Different epidemiological, phenotypical and genetic characteristics among BC subtypes.

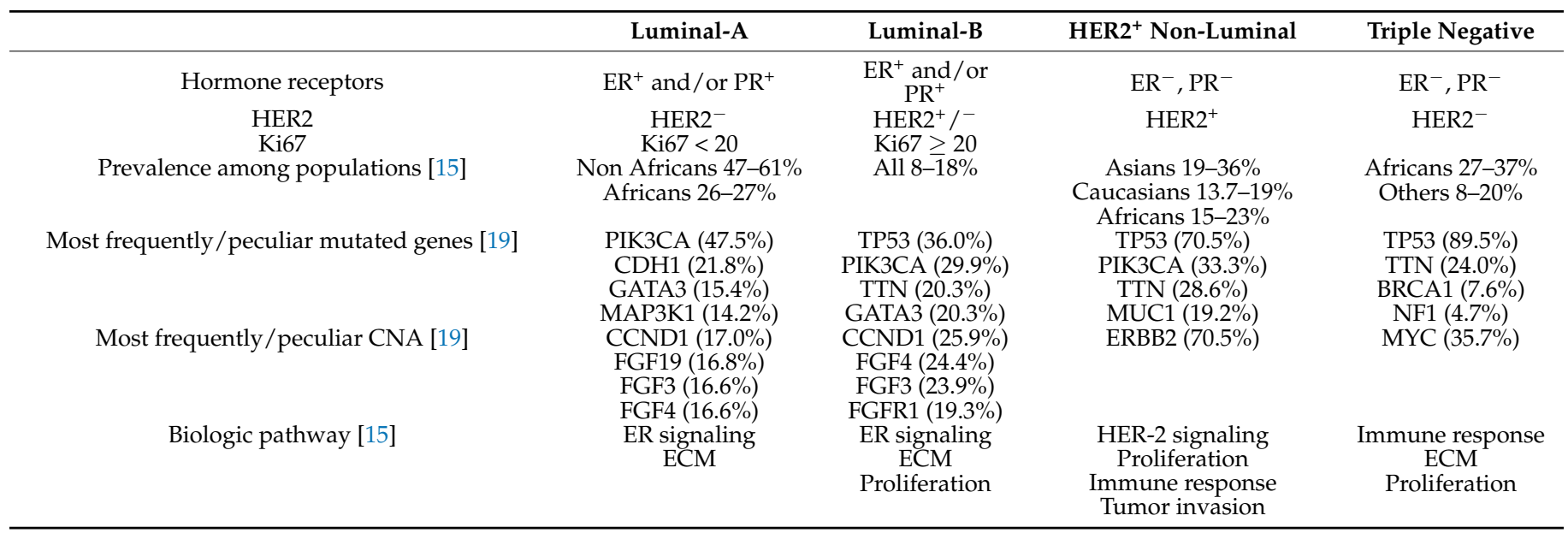

CNA: Copy number alterations, ECM: Extracellular matrix.

The identification of peculiar alterations can also be associated with prognosis or response to therapy. For example, the detection of FGFR1 amplification has been associated with an increased risk of late recurrences in ER-positive BC [20], or PIK3CA mutations have been considered predictive of neoadjuvant chemotherapy resistance in HER2 positive BCs [16]. Furthermore, different pathological features can result in different prognostic value according to different $B C$ subtypes. The presence of TILs has a prognostic significance in HER2 positive and triple negative breast cancers where a higher stromal lymphocytic infiltration has been associated with better prognosis, but this was not confirmed in luminal tumors [21-23].

\section{Intra-Tumor Heterogeneity}

Intra-tumor heterogeneity refers to the heterogeneity seen between different regions of a primary tumor, between a primary tumor and a metastatic lesion, or among different metastatic lesions. Indeed, differences in the tumor genome, epigenome, transcriptome and proteome could be revealed in different phenotypes, creating diagnostic and therapeutic challenges. In addition, heterogeneity of phenotypes within the same tumor can be influenced by the surrounding microenvironment. The extracellular matrix $(\mathrm{ECM})$ is the major component of the local microenvironment—niche—of cancer cells. The ECM is a complex network of macromolecules such as proteins, proteoglycans, and polysaccharides with different physical, biochemical, and biomechanical properties. There is a bidirectional communication between tumor cells and the ECM through cell-matrix interactions resulting in a dynamic remodeling of ECM. The deregulation of ECM remodeling, including changes in the three-dimensional spatial organization of ECM and of its biochemical and physical properties, can create a microenvironment that promotes tumorigenesis and metastasis [24,25]. Indeed, stromal desmoplasia, characterized by excessive deposition of fibrillary collagen in the surroundings of the tumor, is very common in BC. Bundles of straightened and aligned collagen fibers perpendicularly oriented to the tumor boundary are supportive of invasive tumor growth [26]. Organoid models may offer the possibility of investigating in vitro the tumor microenvironment, capturing functional parameters related to tumor heterogeneity [27]. However, these models should be used with caution because they cannot reflect the complexity of the dialogue among the components of microenvironment in vivo. Recent advances in transcriptomic and proteomic studies at a single cell level could probably offer new insight in this field $[25,28]$.

\subsection{Spatial Heterogeneity}

Spatial heterogeneity refers to heterogeneity occurring among different geographical regions of the same tumor. 
Morphologically distinct regions of a tumor can exhibit different mutational landscapes, associated with distinct genetic aberrations $[29,30]$. The sub-clonal structure of primary BC is of paramount importance for tumor evolution and therapy response. NikZainal et al. performed whole-genome sequencing analyses coupled with bioinformatic algorithms for the phylogenetic tree design across 21 primary breast tumors of different subtypes and revealed that several subclones were present in each tumor, harboring different somatic mutations, copy-number aberrations, and chromosomal rearrangements [31,32]. Moreover, Yates reported that potentially targetable mutations were sub-clonal and markers of disease progression arose within detectable subclones of antecedent lesions [33]. Interestingly, the sub-clonal architecture may develop in a nonrandom way for a tumor cell contact-mediated mechanism that could induce clonal expansion of specific subclones, as recently described in association with HER2:PIK3CA mutated clonal dynamics and fibronectin expression [34].

In addition, the intra-tumor heterogeneity has also been correlated to different immune microenvironments. In the same tumor, a heterogeneous pattern of Tumor-Infiltrating Lymphocytes (TILs) can be observed, with different composition of immune cell subpopulations [35-37]. Lymphocytes have a highly mobile nature and can lead to rapidly changing spatial heterogeneity, resulting in immunologically active or silent niches, crucial for response to immunotherapy. Moreover, a heterogeneous immunohistochemical expression of MMR protein has been recently reported in more than $12 \%$ of BCs [38]. The relative frequency of heterogeneous protein expression ranged from 33\% for PMS2 to $50 \%$ for MSH6, with higher rates in luminal tumors. Even the PD-L1 expression exhibits spatial heterogeneity in both the tumor cells and the infiltrating immune cells or node lymphocytes in primary tumors and lymph nodal metastases [39]. All these findings suggest that the analysis of a single area of the tumor may not represent the status of the whole breast tumor. Therefore, even the gene signatures assays such as Oncotype or Mammaprint, valuable tools for recurrence prediction and treatment decision making, may be influenced by tumor heterogeneity. As highlighted in the study of Gyanchandani et al., in highly heterogeneous tumors the evaluation of a single tumor core could under- or overestimate the recurrence risk. In this scenario, the analysis of the most heterogeneous sections or the assessment of multiple core of the same BC, reflecting the intra-tumor heterogeneity, could be effective strategies to apply for the performance of clinically useful gene expression panels [40].

The levels of uniformity or heterogeneity of specific markers within the same tumor have an important clinical value as they have been recently associated to prognosis and therapy response. ERBB2 gene amplification assessed by fluorescence in situ hybridization (FISH) or HER2 protein overexpression assessed by immunohistochemistry are the main primary predictors of responsiveness to HER2-targeted therapies in BC. In HER2 positive $B C$, a heterogeneous HER2 immunohistochemical staining and ERBB2 gene amplification evaluated by FISH have been associated with shorter survival and tumor progression [41-43]. Moreover, in HER2 positive BC, the response to HER2-targeted therapy could be modulated by the level of HER2 heterogeneity, defined as an area with ERBB2 amplification in $>5 \%$ but $<50 \%$ of tumor cells, or a HER 2 negative area by FISH. Patients with a higher level of heterogeneity are less likely to have a complete pathologic response to neoadjuvant pertuzumab and T-DM1 treatment [44]. Even the response to endocrine therapy is related to the level and uniformity of ER expression: tumors strongly expressing ER in the majority of tumor cells show a better outcome than ER-heterogeneous tumors $[45,46]$ whereas intra-metastatic ER heterogeneity has been reported as an independent predictor of poor patient survival [47].

\subsection{Temporal Heterogeneity}

Temporal heterogeneity refers to the evolution of a tumor over time, including the transition from in situ breast carcinoma to invasive cancer and to metastatic disease. The tumor is a dynamic entity that can change during progression. The tumor modeling is a result of additional genetic alterations acquired during cancer progression but also as 
a consequence of treatments in selecting therapy resistant clones, or influenced by the tumor-stroma-immune system interactions [48].

The most relevant evidence of temporal heterogeneity is the discordance in terms of ER, PR and HER2 expression that could emerge between primary tumors and their matched metastatic lesions. Discordant expression rates can be observed in a not irrelevant quota of patients and varies from 9-30\% for ER, 15-45\% for PR and 4-16\% for HER2 expressions, and can affect tumor behavior and treatment response [49-57]. According to PAM50 gene expression, breast primary tumors shift toward unfavorable subtypes in metastases, with a worse prognosis associated with a change from luminal primary tumor to nonluminal distant metastasis [58]. The status of ER, PR, HER2 and Ki-67 expression can also change following neoadjuvant treatment (NAT). The biomarker status change after NAT is common, affecting approximately $30 \%$ of patients and has prognostic value $[59,60]$. In particular, no biomarker change is associated with improved survival whereas the shift from $\mathrm{HR}^{+} / \mathrm{HER}^{-}$to $\mathrm{HR}^{-} / \mathrm{HER} 2^{-}$is associated with worse prognosis $[59,60]$. Consequently, the retesting of hormone receptors and HER2 status after NAT and at relapse may be useful both for prognosis and treatment purposes.

Another observation is the PD-L1 immunohistochemical staining discrepancy between primary tumors and metastases. A recent meta-analysis indicates that pooled PD-L1 positivity rate, considering both tumor and immune cells, was higher in primary breast tumors compared to metastases. However, PD-L1 discordance between primary BC and metastasis was bi-directional and was more common when PD-L1 expression was assessed in immune cells only [61].

Recent NGS analyses evaluating paired primary tumors and matched metastatic lesions confirm the molecular heterogeneity underpinning metastatic progression [17,62-65]. Interestingly, a quota of mutations arisen during the metastatic process could be targeted by biological drugs (e.g., affecting ERBB2, BRCA2, PIK3CA) [66]. In our recent study we evaluated primary tumors and matched relapses of 61 patients affected by BC. We detected in $39(63.9 \%)$ cases additional private alterations in the relapse samples only, including 12 $(19.7 \%)$ of patients with potentially actionable aberrations [17]. Moreover, the extent of temporal intra-tumor heterogeneity detected might be proportional to the time elapsed between the diagnosis of the primary tumor and the occurrence of metastatic relapse, as the longer the time, the higher the extent of heterogeneity $[17,65]$.

Primary cancers have more clonal variability in terms of mutations and structural modifications than their metastatic counterparts, suggesting that therapy may lead to clonal selection. On the other hand, the therapy could induce molecular changes emerging during/after treatments as the enrichment in MCL1, JAK2, CDK6/CCND1-3 gene copy number gain detected by massive parallel sequencing and PTEN deletions and/or mutations in the post-neoadjuvant-chemotherapy setting of TNBC [67]. Patients with BRCA1/2 alterations treated with poly(ADP) ribose polymerase (PARP) inhibitors and platinum-based chemotherapy could develop resistance as a result of secondary mutations in BRCA1/2 genes [68]. Moreover, ESR1 mutation onset in recurrent disease of luminal primary tumors treated with endocrine therapies is a marker of endocrine therapy resistance and disease progression. The infrequent ESR1 alterations found in treatment-naive tumors suggest that the selective pressure of treatment may lead to clonal expansion of rare mutant clones [69-71].

A pivotal contribution to understanding the dynamic changes occurring during BC progression has been recently added by the molecular screening initiative-AURORA program - of the Breast International Group. The AURORA program aimed to evaluate the processes of relapse in metastatic breast cancer, performing analysis of the genomic and transcriptomic profile of paired primary BC and metastases of 381 patients. They identified genomic alterations enriched in metastases namely ESR1, PTEN, CDH1, PIK3CA and RB1 mutations, MDM4 and MYC gene copy number gains, and ARID1A deletions. Moreover, ESMO Scale of Clinical Actionability for molecular Targets (ESCAT) tier I/II alterations were detected in over half of the patients, with crucial impact for target therapy 
selection; on the other hand, metastases had lower immune score and an increased number of immune permissive cells [62].

All these findings highlight the importance of evaluating the metastatic disease for planning the most effective-single patient tailored-therapeutic strategy.

\section{Clinical Implications of Tumor Heterogeneity}

Tumor heterogeneity poses important clinical challenges, both for prognosis and response to therapy. The identification of intra-tumor heterogeneity itself, whether within the primary tumors or between primary tumor and metastatic counterparts or intra-metastatic, is a hallmark of malignancy, linked to poor patient outcomes [72-74]. From a therapeutic point of view, inter-tumor heterogeneity implies that each breast cancer can be different in every patient, foreclosing 'one-size-fits-all' treatment approaches. In addition, the presence of different tumoral clones within an individual tumor adds more difficulties for the selection of the most effective therapy [75]. Indeed, intra-tumor heterogeneity entails that targeting the predominant aberrations might not be effective against all the tumoral clones, but the selective pressure of anticancer treatments may lead to the expansion of different resistant subclones [72-74]. Patient-derived tumor xenograft (PDTXs) can be useful models for mirroring the BC inter- and intra-tumor heterogeneity and can be adopted for in vitro drug screening and in vivo predicting drug response [76,77]. Recently Georgopoulou et al. applied a single-cell breast cancer mass cytometry (BCMC) panel in a biobank of PDTX models and showed that different tumor cell phenotypes with distinct drug sensitivities can coexist in the same tumors and display different dynamics under therapy [78].

Currently tumor heterogeneity is still not commonly evaluated in clinical practice, as the major issue is how to assess it. In the primary setting, the combination of digital pathology with automated image analysis of the whole tumor tissue section could be a useful tool to capture intra-tumor heterogeneity $[79,80]$ but in the metastatic setting this is more challenging. Evaluating the genomic landscape of cancer through a single tumor biopsy gives a spatial- and temporal snapshot of the disease. On the contrary, liquid biopsy, including circulating tumor DNA (ctDNA) and circulating tumor cells (CTC), could be more representative of the temporal and spatial heterogeneity of the breast cancer genome [81]. The liquid biopsy approach could be useful not only for the repeatability over time, essential for the monitoring of tumor progression, but also because the circulating tumor biomarkers may derive from clones with higher metastatic potential that should be targeted [82-84]. A proof of liquid biopsy's usefulness in the management of BC patients is the detection of ESR1 mutations in ctDNA obtained from plasma of ER-positive metastatic $\mathrm{BC}$ patients, a biomarker of aromatase inhibitor therapy resistance [85].

Another non-invasive and promising approach, rapidly expanding in recent years, is the use of radiomics. Radiomics can extract high-throughput quantitative data from non-invasive radiological images, improving cancer diagnosis and treatment [86-88]. The radiogenomics correlates radiomic features and genomic characteristics, with the goal of identifying clinically relevant molecular alterations associated with outcomes. Compared to the traditional biopsy of metastatic lesion approach, radiogenomic analyses are non-invasive and easily repeatable and may become a surrogate for tissue-based genomic analyses. Moreover, the radiogenomics analysis can capture intra-tumor spatial heterogeneity, assuming a clinically relevant prognostic value. Indeed, in a recent study the radio-genomic signatures of imaging scale heterogeneity were used to classify patients affected by breast cancer into groups with distinct subclone compositions, linked to prognosis [89].

\section{Conclusions}

Breast cancer is widely characterized by phenomena of heterogeneity. Inter-tumor and intra-tumor heterogeneity, spatial and temporal differences concerning phenotypic and genotypic aspects, have a clear impact on the clinical management of BC patients, affecting prognosis and therapy response. The tumor genetic landscape could change during tumor 
progression, hence the need to evaluate metastatic biopsies to assess the best-i.e., single patient tailored-therapeutic strategy for patients with recurrent disease. Moreover, the treatment response or the onset of resistance mechanisms should be strictly followed for a tuning of the powerful therapeutic strategy as a combination of agents that target different driver mutations. In this scenario, radiogenomics and liquid biopsy tools might be the future, having the potential to capture BC heterogeneity in a non-invasive way.

Author Contributions: C.F. and M.B.: writing-review and editing. All authors have read and agreed to the published version of the manuscript.

Funding: This work was partially supported by the Italian Ministry of Health with Ricerca Corrente and $5 \times 1000$ funds.

Institutional Review Board Statement: Not applicable.

Informed Consent Statement: Not applicable.

Data Availability Statement: Not applicable.

Conflicts of Interest: The authors declare no conflict of interest.

\section{References}

1. Sung, H.; Ferlay, J.; Siegel, R.L.; Laversanne, M.; Soerjomataram, I.; Jemal, A.; Bray, F. Global Cancer Statistics 2020: Globocan Estimates of Incidence and Mortality Worldwide for 36 Cancers in 185 Countries. CA Cancer J. Clin. 2021, 71, 209-249. [CrossRef]

2. Young, R.H.; Louis, D.N. The Warrens and Other Pioneering Clinician Pathologists of the Massachusetts General Hospital during Its Early Years: An Appreciation on the 200th Anniversary of the Hospital Founding. Mod. Pathol. 2011, 24, 1285-1294. [CrossRef]

3. Hawkins, R.A.; Killen, E.; Tesdale, A.L.; Sangster, K.; Thomson, M.; Steele, R.J.C.; Blackie, R.A.S. Oestrogen Receptors, Lactate Dehydrogenase and Cellularity in Human Breast Cancer. Clin. Chim. Acta 1988, 175, 89-96. [CrossRef]

4. Turashvili, G.; Brogi, E. Tumor Heterogeneity in Breast Cancer. Front. Med. 2017, 4, 227. [CrossRef] [PubMed]

5. Vogelstein, B.; Papadopoulos, N.; Velculescu, V.E.; Zhou, S.; Diaz, L.A.; Kinzler, K.W. Cancer Genome Landscapes. Science 2013, 339, 1546-1558. [CrossRef]

6. Marusyk, A.; Almendro, V.; Polyak, K. Intra-Tumour Heterogeneity: A Looking Glass for Cancer? Nat. Rev. Cancer 2012, 12, 323-334. [CrossRef] [PubMed]

7. Fane, M.; Weeraratna, A.T. How the Ageing Microenvironment Influences Tumour Progression. Nat. Rev. Cancer 2020, 20, 89-106. [CrossRef] [PubMed]

8. Dunnwald, L.K.; Rossing, M.A.; Li, C.I. Hormone Receptor Status, Tumor Characteristics, and Prognosis: A Prospective Cohort of Breast Cancer Patients. Breast Cancer Res. 2007, 9, R6. [CrossRef]

9. Davis, S.L.; Eckhardt, S.G.; Tentler, J.J.; Diamond, J.R. Triple-Negative Breast Cancer: Bridging the Gap from Cancer Genomics to Predictive Biomarkers. Ther. Adv. Med. Oncol. 2014, 6, 88-100. [CrossRef]

10. Vogel, C.L.; Cobleigh, M.A.; Tripathy, D.; Gutheil, J.C.; Harris, L.N.; Fehrenbacher, L.; Slamon, D.J.; Murphy, M.; Novotny, W.F.; Burchmore, M.; et al. Efficacy and Safety of Trastuzumab as a Single Agent in First-Line Treatment of HER2-Overexpressing Metastatic Breast Cancer. JCO 2002, 20, 719-726. [CrossRef] [PubMed]

11. Early Breast Cancer Trialists' Collaborative Group. Effects of Chemotherapy and Hormonal Therapy for Early Breast Cancer on Recurrence and 15-Year Survival: An Overview of the Randomised Trials. Lancet 2005, 365, 1687-1717. [CrossRef]

12. Nanda, R.; Chow, L.Q.M.; Dees, E.C.; Berger, R.; Gupta, S.; Geva, R.; Pusztai, L.; Pathiraja, K.; Aktan, G.; Cheng, J.D.; et al. Pembrolizumab in Patients With Advanced Triple-Negative Breast Cancer: Phase Ib KEYNOTE-012 Study. JCO 2016, 34, 2460-2467. [CrossRef]

13. Emens, L.A.; Adams, S.; Barrios, C.H.; Diéras, V.; Iwata, H.; Loi, S.; Rugo, H.S.; Schneeweiss, A.; Winer, E.P.; Patel, S.; et al. First-Line Atezolizumab plus Nab-Paclitaxel for Unresectable, Locally Advanced, or Metastatic Triple-Negative Breast Cancer: IMpassion130 Final Overall Survival Analysis. Ann. Oncol. 2021, 32, 983-993. [CrossRef] [PubMed]

14. Xu, J.; Bao, H.; Wu, X.; Wang, X.; Shao, Y.; Sun, T. Elevated Tumor Mutation Burden and Immunogenic Activity in Patients with Hormone Receptor-negative or Human Epidermal Growth Factor Receptor 2-positive Breast Cancer. Oncol. Lett. 2019, 18, 449-455. [CrossRef]

15. Ebili, H.O.; Oluwasola, A.O.; Olopade, O.I. Molecular subtypes and prognosis of breast cancer. In Personalized Management of Breast Cancer; Jatoi, I., Holloway, T.L., Eds.; Future Medicine Ltd.: London, UK, 2014; pp. 21-33. [CrossRef]

16. Loibl, S.; Treue, D.; Budczies, J.; Weber, K.; Stenzinger, A.; Schmitt, W.D.; Weichert, W.; Jank, P.; Furlanetto, J.; Klauschen, F.; et al. Mutational Diversity and Therapy Response in Breast Cancer: A Sequencing Analysis in the Neoadjuvant GeparSepto Trial. Clin. Cancer Res. 2019, 25, 3986-3995. [CrossRef] [PubMed]

17. Fumagalli, C.; Ranghiero, A.; Gandini, S.; Corso, F.; Taormina, S.; De Camilli, E.; Rappa, A.; Vacirca, D.; Viale, G.; Guerini-Rocco, E.; et al. Inter-Tumor Genomic Heterogeneity of Breast Cancers: Comprehensive Genomic Profile of Primary Early Breast Cancers and Relapses. Breast Cancer Res. 2020, 22, 107. [CrossRef] 
18. Denkert, C.; Liedtke, C.; Tutt, A.; von Minckwitz, G. Molecular Alterations in Triple-Negative Breast Cancer-The Road to New Treatment Strategies. Lancet 2017, 389, 2430-2442. [CrossRef]

19. CBIOPORTAL DATABASE. Available online: http:/ / cbioportal.org (accessed on 17 July 2021).

20. Guerini-Rocco, E.; Gray, K.P.; Fumagalli, C.; Reforgiato, M.R.; Leone, I.; Rafaniello Raviele, P.; Munzone, E.; Kammler, R.; Neven, P.; Hitre, E.; et al. Genomic Aberrations and Late Recurrence in Postmenopausal Women with Hormone Receptor-Positive Early Breast Cancer: Results from the SOLE Trial. Clin. Cancer Res. 2021, 27, 504-512. [CrossRef] [PubMed]

21. Adams, S.; Gray, R.J.; Demaria, S.; Goldstein, L.; Perez, E.A.; Shulman, L.N.; Martino, S.; Wang, M.; Jones, V.E.; Saphner, T.J.; et al. Prognostic Value of Tumor-Infiltrating Lymphocytes in Triple-Negative Breast Cancers from Two Phase III Randomized Adjuvant Breast Cancer Trials: ECOG 2197 and ECOG 1199. JCO 2014, 32, 2959-2966. [CrossRef] [PubMed]

22. Mao, Y.; Qu, Q.; Chen, X.; Huang, O.; Wu, J.; Shen, K. The Prognostic Value of Tumor-Infiltrating Lymphocytes in Breast Cancer: A Systematic Review and Meta-Analysis. PLoS ONE 2016, 11, e0152500. [CrossRef]

23. Lotfinejad, P.; Asghari Jafarabadi, M.; Abdoli Shadbad, M.; Kazemi, T.; Pashazadeh, F.; Sandoghchian Shotorbani, S.; Jadidi Niaragh, F.; Baghbanzadeh, A.; Vahed, N.; Silvestris, N.; et al. Prognostic Role and Clinical Significance of TumorInfiltrating Lymphocyte (TIL) and Programmed Death Ligand 1 (PD-L1) Expression in Triple-Negative Breast Cancer (TNBC): A Systematic Review and Meta-Analysis Study. Diagnostics 2020, 10, 704. [CrossRef]

24. Lu, P.; Weaver, V.M.; Werb, Z. The extracellular matrix: A dynamic niche in cancer progression. J. Cell Biol. 2012, 196, 395-406. [CrossRef]

25. Winkler, J.; Abisoye-Ogunniyan, A.; Metcalf, K.J.; Werb, Z. Concepts of extracellular matrix remodelling in tumour progression and metastasis. Nat. Commun. 2020, 11, 5120. [CrossRef]

26. Conklin, M.W.; Eickhoff, J.; Riching, K.M.; Pehlke, C.A.; Eliceiri, K.W.; Provenzano, P.P.; Friedl, A.; Keely, P.J. Aligned collagen is a prognostic signature for survival in human breast carcinoma. Am. J. Pathol. 2011, 178, 1221-1232. [CrossRef]

27. Sachs, N.; de Ligt, J.; Kopper, O.; Gogola, E.; Bounova, G.; Weeber, F.; Balgobind, A.V.; Wind, K.; Gracanin, A.; Begthel, H.; et al. Living Biobank of Breast Cancer Organoids Captures Disease Heterogeneity. Cell 2018, 172, 373-386.e10. [CrossRef]

28. Keren, L.; Bosse, M.; Marquez, D.; Angoshtari, R.; Jain, S.; Varma, S.; Yang, S.R.; Kurian, A.; Van Valen, D.; West, R.; et al. Structured Tumor-Immune Microenvironment in Triple Negative Breast Cancer Revealed by Multiplexed Ion Beam Imaging. Cell 2018, 174, 1373-1387.e19. [CrossRef] [PubMed]

29. Yates, L.R. Intratumoral Heterogeneity and Subclonal Diversification of Early Breast Cancer. Breast 2017, 34, S36-S42. [CrossRef]

30. Patani, N.; Barbashina, V.; Lambros, M.B.K.; Gauthier, A.; Mansour, M.; Mackay, A.; Reis-Filho, J.S. Direct Evidence for Concurrent Morphological and Genetic Heterogeneity in an Invasive Ductal Carcinoma of Triple-Negative Phenotype. J. Clin. Pathol. 2011, 64, 822-828. [CrossRef] [PubMed]

31. Nik-Zainal, S.; Alexandrov, L.B.; Wedge, D.C.; Van Loo, P.; Greenman, C.D.; Raine, K.; Jones, D.; Hinton, J.; Marshall, J.; Stebbings, L.A.; et al. Mutational Processes Molding the Genomes of 21 Breast Cancers. Cell 2012, 149, 979-993. [CrossRef]

32. Nik-Zainal, S.; Van Loo, P.; Wedge, D.C.; Alexandrov, L.B.; Greenman, C.D.; Lau, K.W.; Raine, K.; Jones, D.; Marshall, J.; Ramakrishna, M.; et al. The Life History of 21 Breast Cancers. Cell 2012, 149, 994-1007. [CrossRef] [PubMed]

33. Yates, L.R.; Gerstung, M.; Knappskog, S.; Desmedt, C.; Gundem, G.; Van Loo, P.; Aas, T.; Alexandrov, L.B.; Larsimont, D.; Davies, H.; et al. Subclonal Diversification of Primary Breast Cancer Revealed by Multiregion Sequencing. Nat. Med. 2015, 21, 751-759. [CrossRef]

34. Karthikeyan, S.; Waters, I.G.; Dennison, L.; Chu, D.; Donaldson, J.; Shin, D.H.; Rosen, D.M.; Gonzalez-Ericsson, P.I.; Sanchez, V.; Sanders, M.E.; et al. Hierarchical Tumor Heterogeneity Mediated by Cell Contact between Distinct Genetic Subclones. J. Clin. Investig. 2021, 131, e143557. [CrossRef] [PubMed]

35. Salgado, R.; Denkert, C.; Demaria, S.; Sirtaine, N.; Klauschen, F.; Pruneri, G.; Wienert, S.; Van den Eynden, G.; Baehner, F.L.; Penault-Llorca, F.; et al. The Evaluation of Tumor-Infiltrating Lymphocytes (TILs) in Breast Cancer: Recommendations by an International TILs Working Group 2014. Ann. Oncol. 2015, 26, 259-271. [CrossRef]

36. Kato, T.; Park, J.-H.; Kiyotani, K.; Ikeda, Y.; Miyoshi, Y.; Nakamura, Y. Integrated Analysis of Somatic Mutations and Immune Microenvironment of Multiple Regions in Breast Cancers. Oncotarget 2017, 8, 62029-62038. [CrossRef]

37. Berben, L.; Wildiers, H.; Marcelis, L.; Antoranz, A.; Bosisio, F.; Hatse, S.; Floris, G. Computerised Scoring Protocol for Identification and Quantification of Different Immune Cell Populations in Breast Tumour Regions by the Use of QuPath Software. Histopathology 2020, 77, 79-91. [CrossRef]

38. Fusco, N.; Lopez, G.; Corti, C.; Pesenti, C.; Colapietro, P.; Ercoli, G.; Gaudioso, G.; Faversani, A.; Gambini, D.; Michelotti, A.; et al. Mismatch Repair Protein Loss as a Prognostic and Predictive Biomarker in Breast Cancers Regardless of Microsatellite Instability. JNCI Cancer Spectr. 2018, 2, pky056. [CrossRef] [PubMed]

39. Li, M.; Li, A.; Zhou, S.; Xu, Y.; Xiao, Y.; Bi, R.; Yang, W. Heterogeneity of PD-L1 Expression in Primary Tumors and Paired Lymph Node Metastases of Triple Negative Breast Cancer. BMC Cancer 2018, 18, 4. [CrossRef] [PubMed]

40. Gyanchandani, R.; Lin, Y.; Lin, H.M.; Cooper, K.; Normolle, D.P.; Brufsky, A.; Fastuca, M.; Crosson, W.; Oesterreich, S.; Davidson, N.E.; et al. Intratumor Heterogeneity Affects Gene Expression Profile Test Prognostic Risk Stratification in Early Breast Cancer. Clin. Cancer Res. 2016, 22, 5362-5369. [CrossRef] [PubMed]

41. Seol, H.; Lee, H.J.; Choi, Y.; Lee, H.E.; Kim, Y.J.; Kim, J.H.; Kang, E.; Kim, S.-W.; Park, S.Y. Intratumoral Heterogeneity of HER2 Gene Amplification in Breast Cancer: Its Clinicopathological Significance. Mod. Pathol. 2012, 25, 938-948. [CrossRef] 
42. Lee, H.J.; Seo, A.N.; Kim, E.J.; Jang, M.H.; Suh, K.J.; Ryu, H.S.; Kim, Y.J.; Kim, J.H.; Im, S.-A.; Gong, G.; et al. HER2 Heterogeneity Affects Trastuzumab Responses and Survival in Patients With HER2-Positive Metastatic Breast Cancer. Am. J. Clin. Pathol. 2014, 142, 755-766. [CrossRef]

43. Hou, Y.; Nitta, H.; Wei, L.; Banks, P.M.; Portier, B.; Parwani, A.V.; Li, Z. HER2 Intratumoral Heterogeneity Is Independently Associated with Incomplete Response to Anti-HER2 Neoadjuvant Chemotherapy in HER2-Positive Breast Carcinoma. Breast Cancer Res. Treat. 2017, 166, 447-457. [CrossRef]

44. Metzger Filho, O.; Viale, G.; Stein, S.; Trippa, L.; Yardley, D.A.; Mayer, I.A.; Abramson, V.G.; Arteaga, C.L.; Spring, L.M.; Waks, A.G.; et al. Impact of HER2 Heterogeneity on Treatment Response of Early-Stage HER2-Positive Breast Cancer: Phase II Neoadjuvant Clinical Trial of T-DM1 Combined with Pertuzumab. Cancer Discov. 2021. [CrossRef]

45. Brouckaert, O.; Paridaens, R.; Floris, G.; Rakha, E.; Osborne, K.; Neven, P. A Critical Review Why Assessment of Steroid Hormone Receptors in Breast Cancer Should Be Quantitative. Ann. Oncol. 2013, 24, 47-53. [CrossRef]

46. Clarke, R.; Liu, M.C.; Bouker, K.B.; Gu, Z.; Lee, R.Y.; Zhu, Y.; Skaar, T.C.; Gomez, B.; O’Brien, K.; Wang, Y.; et al. Antiestrogen Resistance in Breast Cancer and the Role of Estrogen Receptor Signaling. Oncogene 2003, 22, 7316-7339. [CrossRef]

47. Allegra, J.C.; Lippman, M.E.; Thompson, E.B.; Simon, R.; Barlock, A.; Green, L.; Huff, K.K.; Do, H.M.Y.T.; Aitken, S.C.; Warren, R. Estrogen Receptor Status: An Important Variable in Predicting Response to Endocrine Therapy in Metastatic Breast Cancer. Eur. J. Cancer 1980, 16, 323-331. [CrossRef]

48. Schrijver, W.A.M.E.; Suijkerbuijk, K.P.M.; van Gils, C.H.; van der Wall, E.; Moelans, C.B.; van Diest, P.J. Receptor Conversion in Distant Breast Cancer Metastases: A Systematic Review and Meta-Analysis. JNCI J. Natl. Cancer Inst. 2018, 110, 568-580. [CrossRef]

49. Grinda, T.; Joyon, N.; Lusque, A.; Lefèvre, S.; Arnould, L.; Penault-Llorca, F.; Macgrogan, G.; Treilleux, I.; Vincent-Salomon, A.; Haudebourg, J.; et al. Phenotypic Discordance between Primary and Metastatic Breast Cancer in the Large-Scale Real-Life Multicenter French ESME Cohort. NPJ Breast Cancer 2021, 7, 41. [CrossRef]

50. Gomez-Fernandez, C.; Daneshbod, Y.; Nassiri, M.; Milikowski, C.; Alvarez, C.; Nadji, M. Immunohistochemically Determined Estrogen Receptor Phenotype Remains Stable in Recurrent and Metastatic Breast Cancer. Am. J. Clin. Pathol. 2008, 130, 879-882. [CrossRef]

51. Gerlinger, M.; Swanton, C. How Darwinian Models Inform Therapeutic Failure Initiated by Clonal Heterogeneity in Cancer Medicine. Br. J. Cancer 2010, 103, 1139-1143. [CrossRef]

52. Carlsson, J.; Nordgren, H.; Sjöström, J.; Wester, K.; Villman, K.; Bengtsson, N.O.; Ostenstad, B.; Lundqvist, H.; Blomqvist, C. HER2 Expression in Breast Cancer Primary Tumours and Corresponding Metastases. Original Data and Literature Review. Br. J. Cancer 2004, 90, 2344-2348. [CrossRef]

53. van Agthoven, T.; Timmermans, M.; Dorssers, L.C.J.; Henzen-Logmans, S.C. Expression of Estrogen, Progesterone and Epidermal Growth Factor Receptors in Primary and Metastatic Breast Cancer. Int. J. Cancer 1995, 63, 790-793. [CrossRef] [PubMed]

54. Yang, Y.-F.; Liao, Y.-Y.; Yang, M.; Peng, N.-F.; Xie, S.-R.; Xie, Y.-F. Discordances in ER, PR and HER2 Receptors between Primary and Recurrent/Metastatic Lesions and Their Impact on Survival in Breast Cancer Patients. Med. Oncol. 2014, 31, 214. [CrossRef]

55. Peng, L.; Zhang, Z.; Zhao, D.; Zhao, J.; Mao, F.; Sun, Q. Discordance in ER, PR, HER2, and Ki-67 Expression Between Primary and Recurrent/Metastatic Lesions in Patients with Primary Early Stage Breast Cancer and the Clinical Significance: Retrospective Analysis of 75 Cases. Pathol. Oncol. Res. 2021, 27, 599894. [CrossRef] [PubMed]

56. Sari, E.; Guler, G.; Hayran, M.; Gullu, I.; Altundag, K.; Ozisik, Y. Comparative Study of the Immunohistochemical Detection of Hormone Receptor Status and HER-2 Expression in Primary and Paired Recurrent/Metastatic Lesions of Patients with Breast Cancer. Med. Oncol. 2011, 28, 57-63. [CrossRef] [PubMed]

57. Aurilio, G.; Disalvatore, D.; Pruneri, G.; Bagnardi, V.; Viale, G.; Curigliano, G.; Adamoli, L.; Munzone, E.; Sciandivasci, A.; De Vita, F.; et al. A Meta-Analysis of Oestrogen Receptor, Progesterone Receptor and Human Epidermal Growth Factor Receptor 2 Discordance between Primary Breast Cancer and Metastases. Eur. J. Cancer 2014, 50, 277-289. [CrossRef]

58. Jørgensen, C.L.T.; Larsson, A.-M.; Forsare, C.; Aaltonen, K.; Jansson, S.; Bradshaw, R.; Bendahl, P.-O.; Rydén, L. PAM50 Intrinsic Subtype Profiles in Primary and Metastatic Breast Cancer Show a Significant Shift toward More Aggressive Subtypes with Prognostic Implications. Cancers 2021, 13, 1592. [CrossRef]

59. Rossi, L.; Verrico, M.; Tomao, S.; Ricci, F.; Fontana, A.; Spinelli, G.P.; Colonna, M.; Vici, P.-; Tomao, F. Expression of ER, PgR, HER-2, and Ki-67 in core biopsies and in definitive histological specimens in patients with locally advanced breast cancer treated with neoadjuvant chemotherapy. Cancer Chemother. Pharmacol. 2020, 85, 105-111. [CrossRef]

60. Mohan, S.C.; Walcott-Sapp, S.; Lee, M.K.; Srour, M.K.; Kim, S.; Amersi, F.F.; Giuliano, A.E.; Chung, A.P. Alterations in Breast Cancer Biomarkers Following Neoadjuvant Therapy. Ann. Surg. Oncol. 2021. [CrossRef]

61. Boman, C.; Zerdes, I.; Mårtensson, K.; Bergh, J.; Foukakis, T.; Valachis, A.; Matikas, A. Discordance of PD-L1 Status between Primary and Metastatic Breast Cancer: A Systematic Review and Meta-Analysis. Cancer Treat. Rev. 2021, 99, 102257. [CrossRef]

62. Aftimos, P.; Oliveira, M.; Irrthum, A.; Fumagalli, D.; Sotiriou, C.; Nili Gal-Yam, E.; Robson, M.E.; Ndozeng, J.; Di Leo, A.; Ciruelos, E.M.; et al. Genomic and Transcriptomic Analyses of Breast Cancer Primaries and Matched Metastases in AURORA, the Breast International Group (BIG) Molecular Screening Initiative. Cancer Discov. 2021. [CrossRef]

63. Agahozo, M.C.; Sieuwerts, A.M.; Doebar, S.C.; Verhoef, E.I.; Beaufort, C.M.; Ruigrok-Ritstier, K.; de Weerd, V.; Sleddens, H.F.B.M.; Dinjens, W.N.M.; Martens, J.W.M.; et al. PIK3CA Mutations in Ductal Carcinoma in Situ and Adjacent Invasive Breast Cancer. Endocr-Relat. Cancer 2019, 26, 471-482. [CrossRef] [PubMed] 
64. Heselmeyer-Haddad, K.; Berroa Garcia, L.Y.; Bradley, A.; Ortiz-Melendez, C.; Lee, W.-J.; Christensen, R.; Prindiville, S.A.; Calzone, K.A.; Soballe, P.W.; Hu, Y.; et al. Single-Cell Genetic Analysis of Ductal Carcinoma in Situ and Invasive Breast Cancer Reveals Enormous Tumor Heterogeneity yet Conserved Genomic Imbalances and Gain of MYC during Progression. Am. J. Pathol. 2012, 181, 1807-1822. [CrossRef] [PubMed]

65. Hernandez, L.; Wilkerson, P.M.; Lambros, M.B.; Campion-Flora, A.; Rodrigues, D.N.; Gauthier, A.; Cabral, C.; Pawar, V.; Mackay, A.; A'Hern, R.; et al. Genomic and Mutational Profiling of Ductal Carcinomas in Situ and Matched Adjacent Invasive Breast Cancers Reveals Intra-Tumour Genetic Heterogeneity and Clonal Selection. J. Pathol. 2012, 227, 42-52. [CrossRef]

66. Available online: http:/ / oncokb.org (accessed on 17 July 2021).

67. Balko, J.M.; Giltnane, J.M.; Wang, K.; Schwarz, L.J.; Young, C.D.; Cook, R.S.; Owens, P.; Sanders, M.E.; Kuba, M.G.; Sánchez, V.; et al. Molecular Profiling of the Residual Disease of Triple-Negative Breast Cancers after Neoadjuvant Chemotherapy Identifies Actionable Therapeutic Targets. Cancer Discov. 2014, 4, 232-245. [CrossRef] [PubMed]

68. Waks, A.G.; Cohen, O.; Kochupurakkal, B.; Kim, D.; Dunn, C.E.; Buendia Buendia, J.; Wander, S.; Helvie, K.; Lloyd, M.R.; Marini, L.; et al. Reversion and Non-Reversion Mechanisms of Resistance to PARP Inhibitor or Platinum Chemotherapy in BRCA1/2-Mutant Metastatic Breast Cancer. Ann. Oncol. 2020, 31, 590-598. [CrossRef]

69. De Santo, I.; McCartney, A.; Migliaccio, I.; Di Leo, A.; Malorni, L. The Emerging Role of ESR1 Mutations in Luminal Breast Cancer as a Prognostic and Predictive Biomarker of Response to Endocrine Therapy. Cancers 2019, 11, 1894. [CrossRef] [PubMed]

70. Jeselsohn, R.; Buchwalter, G.; De Angelis, C.; Brown, M.; Schiff, R. ESR1 Mutations-A Mechanism for Acquired Endocrine Resistance in Breast Cancer. Nat. Rev. Clin. Oncol 2015, 12, 573-583. [CrossRef] [PubMed]

71. Turner, N.C.; Swift, C.; Kilburn, L.; Fribbens, C.; Beaney, M.; Garcia-Murillas, I.; Budzar, A.U.; Robertson, J.F.R.; Gradishar, W.; Piccart, M.; et al. ESR1 Mutations and Overall Survival on Fulvestrant versus Exemestane in Advanced Hormone ReceptorPositive Breast Cancer: A Combined Analysis of the Phase III SoFEA and EFECT Trials. Clin. Cancer Res. 2020, 26, $5172-5177$. [CrossRef] [PubMed]

72. Turner, N.C.; Reis-Filho, J.S. Genetic Heterogeneity and Cancer Drug Resistance. Lancet Oncol. 2012, 13, e178-e185. [CrossRef]

73. Dagogo-Jack, I.; Shaw, A.T. Tumour Heterogeneity and Resistance to Cancer Therapies. Nat. Rev. Clin. Oncol. 2018, 15, 81-94. [CrossRef]

74. Yates, L.R.; Campbell, P.J. Evolution of the Cancer Genome. Nat. Rev. Genet. 2012, 13, 795-806. [CrossRef]

75. Swanton, C.; Burrell, R.A.; Futreal, P.A. Breast Cancer Genome Heterogeneity: A Challenge to Personalized Medicine? Breast Cancer Res. 2011, 13, 104. [CrossRef]

76. Gao, H.; Korn, J.M.; Ferretti, S.; Monahan, J.E.; Wang, Y.; Singh, M.; Zhang, C.; Schnell, C.; Yang, G.; Zhang, Y.; et al. Highthroughput screening using patient-derived tumor xenografts to predict clinical trial drug response. Nat. Med. 2015, 21, 1318-1325. [CrossRef] [PubMed]

77. Bruna, A.; Rueda, O.M.; Greenwood, W.; Batra, A.S.; Callari, M.; Batra, R.N.; Pogrebniak, K.; Sandoval, J.; Cassidy, J.W.; Tufegdzic-Vidakovic, A.; et al. Biobank of Breast Cancer Explants with Preserved Intra-tumor Heterogeneity to Screen Anticancer Compounds. Cell 2016, 167, 260-274.e22. [CrossRef] [PubMed]

78. Georgopoulou, D.; Callari, M.; Rueda, O.M.; Shea, A.; Martin, A.; Giovannetti, A.; Qosaj, F.; Dariush, A.; Chin, S.F.; Carnevalli, L.S.; et al. Landscapes of cellular phenotypic diversity in breast cancer xenografts and their impact on drug response. Nat. Commun. 2021, 12, 1998. [CrossRef]

79. Zhong, Q.; Rüschoff, J.H.; Guo, T.; Gabrani, M.; Schüffler, P.J.; Rechsteiner, M.; Liu, Y.; Fuchs, T.J.; Rupp, N.J.; Fankhauser, C.; et al. Image-Based Computational Quantification and Visualization of Genetic Alterations and Tumour Heterogeneity. Sci. Rep. 2016, 6, 24146. [CrossRef]

80. Heindl, A.; Nawaz, S.; Yuan, Y. Mapping Spatial Heterogeneity in the Tumor Microenvironment: A New Era for Digital Pathology. Lab. Investig. 2015, 95, 377-384. [CrossRef]

81. Crowley, E.; Di Nicolantonio, F.; Loupakis, F.; Bardelli, A. Liquid Biopsy: Monitoring Cancer-Genetics in the Blood. Nat. Rev. Clin. Oncol. 2013, 10, 472-484. [CrossRef]

82. Smit, D.J.; Pantel, K.; Jücker, M. Circulating Tumor Cells as a Promising Target for Individualized Drug Susceptibility Tests in Cancer Therapy. Biochem. Pharmacol. 2021, 188, 114589. [CrossRef] [PubMed]

83. Forshew, T.; Murtaza, M.; Parkinson, C.; Gale, D.; Tsui, D.W.Y.; Kaper, F.; Dawson, S.-J.; Piskorz, A.M.; Jimenez-Linan, M.; Bentley, D.; et al. Noninvasive Identification and Monitoring of Cancer Mutations by Targeted Deep Sequencing of Plasma DNA. Sci. Transl. Med. 2012, 4, 136ra68. [CrossRef] [PubMed]

84. Onstenk, W.; Gratama, J.W.; Foekens, J.A.; Sleijfer, S. Towards a Personalized Breast Cancer Treatment Approach Guided by Circulating Tumor Cell (CTC) Characteristics. Cancer Treat. Rev. 2013, 39, 691-700. [CrossRef] [PubMed]

85. Schiavon, G.; Hrebien, S.; Garcia-Murillas, I.; Cutts, R.J.; Pearson, A.; Tarazona, N.; Fenwick, K.; Kozarewa, I.; Lopez-Knowles, E.; Ribas, R.; et al. Analysis of ESR1 Mutation in Circulating Tumor DNA Demonstrates Evolution during Therapy for Metastatic Breast Cancer. Sci. Transl. Med. 2015, 7, 313ra182. [CrossRef] [PubMed]

86. Lambin, P.; Leijenaar, R.T.H.; Deist, T.M.; Peerlings, J.; de Jong, E.E.C.; van Timmeren, J.; Sanduleanu, S.; Larue, R.T.H.M.; Even, A.J.G.; Jochems, A.; et al. Radiomics: The Bridge between Medical Imaging and Personalized Medicine. Nat. Rev. Clin. Oncol. 2017, 14, 749-762. [CrossRef] [PubMed] 
87. Aerts, H.J.W.L.; Velazquez, E.R.; Leijenaar, R.T.H.; Parmar, C.; Grossmann, P.; Carvalho, S.; Bussink, J.; Monshouwer, R.; Haibe-Kains, B.; Rietveld, D.; et al. Decoding Tumour Phenotype by Noninvasive Imaging Using a Quantitative Radiomics Approach. Nat. Commun. 2014, 5, 4006. [CrossRef]

88. Fan, M.; Zhang, P.; Wang, Y.; Peng, W.; Wang, S.; Gao, X.; Xu, M.; Li, L. Radiomic Analysis of Imaging Heterogeneity in Tumours and the Surrounding Parenchyma Based on Unsupervised Decomposition of DCE-MRI for Predicting Molecular Subtypes of Breast Cancer. Eur. Radiol. 2019, 29, 4456-4467. [CrossRef]

89. Fan, M.; Xia, P.; Clarke, R.; Wang, Y.; Li, L. Radiogenomic Signatures Reveal Multiscale Intratumour Heterogeneity Associated with Biological Functions and Survival in Breast Cancer. Nat. Commun. 2020, 11, 4861. [CrossRef] 